\title{
Effect of acid etching on marginal adaptation of mineral trioxide aggregate to apical dentin: microcomputed tomography and scanning electron microscopy analysis
}

\author{
Khalid Al-Fouzan $^{1,2}$, Ziad Al-Garawi ${ }^{1,3}$, Khalid Al-Hezaimi ${ }^{1,4}$, Fawad Javed ${ }^{1}$, Thakib Al-Shalan ${ }^{1,4}$ \\ and Ilan Rotstein ${ }^{5}$
}

\begin{abstract}
The present investigation assessed the effect of acid etching on marginal adaptation of white- and gray-colored mineral trioxide aggregate (MTA) to apical dentin using microcomputed tomography (micro-CT) and scanning electron microscopy (SEM). Sixty-four extracted single-rooted human maxillary teeth were used. Following root-end resection and apical preparation, the teeth were equally divided into four groups according to the following root end filling materials: (i) white-colored MTA (WMTA), (ii) etched WMTA (EWMTA), (iii) gray-colored MTA (GMTA) and (iv) etched GMTA (EGMTA). After $48 \mathrm{~h}$, the interface between root-end filling materials and the dentinal walls was assessed using micro-CT and SEM. Data were statistically analyzed using the Kruskal-Wallis and Dunn tests. Micro-CT analysis revealed gap volumes between the apical cavity dentin walls and EGMTA, GMTA, EWMTA and WMTA of $(0.0071 \pm 0.004) \mathrm{mm}^{3},(0.053 \pm 0.002) \mathrm{mm}^{3},(0.0036 \pm 0.001) \mathrm{mm}^{3}$ and $(0.0059 \pm 0.002) \mathrm{mm}^{3}$ respectively. SEM analysis revealed gap sizes for EGMTA, WMTA, EWMTA and GMTA to be $(492.3 \pm 13.8) \mu \mathrm{m}$, $(594.5 \pm 17.12) \mu \mathrm{m},(543.1 \pm 15.33) \mu \mathrm{m}$ and $(910.7 \pm 26.2) \mu \mathrm{m}$ respectively. A significant difference in gap size between root end preparations filled with GMTA and EGMTA was found $(P<0.05)$. No significance difference in gap size between WMTA and EWMTA were found in either SEM or micro-CT analysis. In conclusion, pre-etching of apical dentin can provide a better seal for GMTA but not for WMTA. International Journal of Oral Science (2012) 4, 202-207; doi:10.1038/ijos.2012.77; published online 10 January 2013
\end{abstract}

Keywords: acid etching; biocompatibility; mineral trioxide aggregate; root end filling

\section{INTRODUCTION}

Apical surgery is usually indicated when conventional non-surgical root canal treatment fails to resolve periapical lesions of endodontic origin. This process involves surgical removal of infected tissues, rootend resection, preparation of a root-end cavity and placement of a root-end filling material. ${ }^{1}$ Inappropriate apical seal and poor marginal adaptation of the filling material to the root-end cavity may affect the prognosis of periapical surgery. ${ }^{2-4}$

Mineral trioxide aggregate (MTA) has been recognized as a suitable root-end filling material following periradicular surgery due to its biocompatibility, antimicrobial efficacy, ability to set in a wet or bleeding environment and capacity to promote biomineralization. ${ }^{5-15}$ The material is commercially available as white-colored MTA (WMTA) or gray-colored MTA (GMTA), both preparations being essentially $75 \%$ Portland cement, $20 \%$ bismuth oxide and $5 \%$ gypsum by weight. ${ }^{11}$ MTA also exhibits certain clinical challenges such as prolonged setting time, potential tooth discoloration (gray-colored preparation), relative high cost and sensitive handling properties. ${ }^{2-3,13}$

Scanning electron microscopy (SEM) studies ${ }^{16-19}$ have reported conflicting results with reference to the marginal adaptation of MTA to root-canal walls. For example, Torabinejad et al. ${ }^{16}$ and Shipper et al..$^{17}$ reported that MTA yields a superior marginal adaptation as compared to amalgam and intermediate restorative material. On the contrary, Bidar et al. ${ }^{18}$ reported no differences between GMTA and WMTA in terms of marginal adaptation.

Komabayashi and Spångberg ${ }^{19}$ reported that some particles of MTA have a diameter of nearly $1.5 \mu \mathrm{m}$, which is smaller than the diameter of some dentinal tubules. This suggests that acid etching of canal walls following removal of the smear layer may yield a better adaptation of the aggregate to the root canal. In turn, it may help achieve a durable seal between the root canal and MTA. The hypothesis of this study was that acid etching of apical dentin improves the marginal adaptation and interface between MTA preparations and dentin walls. The purpose of this study was to assess the effect of pre-etching of the apical dentin on the marginal adaptation of MTA preparations to the apical root dentin using SEM and microcomputed tomography (micro-CT) analysis.

\section{MATERIALS AND METHODS}

Sixty-four single-rooted intact human maxillary teeth, extracted for periodontal reasons, were used. Teeth with significant apical curvatures,

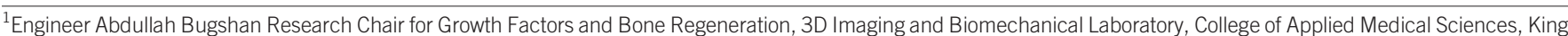

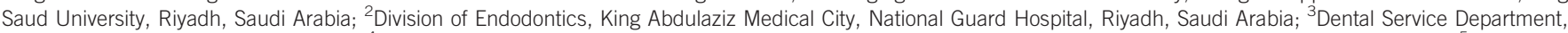

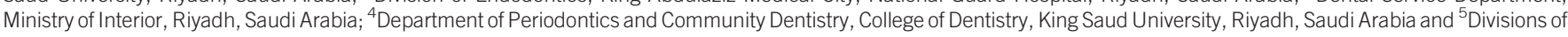
Endodontics, Oral \& Maxillofacial Surgery and Orthodontics, Herman Ostrow School of Dentistry of University of Southern California, Los Angeles, USA

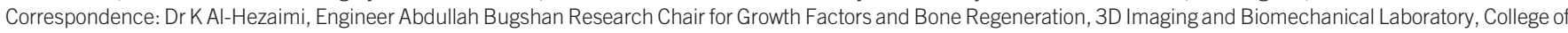
Applied Medical Sciences, King Saud University, PO Box 60169, Riyadh 11545, Saudi Arabia

E-mail: hezaimik16@gmail.com

Received 8 February 2012; accepted 26 November 2012 
root fractures, root caries or root resorption were excluded. Prior to initiation of the study, the teeth were stored at $4{ }^{\circ} \mathrm{C}$ in $0.9 \%$ sodium chloride solution supplemented with $0.02 \%$ sodium azide to prevent bacterial growth.

\section{Root canal preparation}

Access cavity was performed in each tooth with a \#2 size round tungsten bur (Brassler, Savannah, GA, USA) mounted on a high-speed hand piece (Dentsply, York, PA, USA). Sterile saline was used as coolant. Canal patency was achieved by passing a size \#10 K-file (Dentsply-Maillefer, Ballaigues, Switzerland) in the root canal until its tip was visible at the apical foramen. Root canals were instrumented using stainless steel Kfiles \#10, 15, 20 (Dentsply-Maillefer, Ballaigues, Switzerland) and a commercial preparation containing ethylenediaminetetraacetic acid (Glyde, Dentsply-Maillefer, Ballaigues, Switzerland) to the working length, established $1 \mathrm{~mm}$ from the apical foramen. Canal shaping was achieved using ProTaper rotary nickel-titanium files (Dentsply-Maillefer, Tulsa, OK, USA) to F2 size ( $8 \%$ taper, 20/100 tip diameter). Root canals were irrigated between each instrument with $2 \mathrm{~mL}$ of $5.25 \%$ sodium hypochlorite, dried and obturated using warm vertical condensation of F2 calibrated gutta-percha points (Dentsply-Maillefer, Tulsa, OK, USA) and AH26 sealer (Dentsply-DeTrey, Konstanz, Germany).

\section{Apical resection and root end preparation}

Once the sealer had set, the teeth were stored in artificial saliva in an aerobic environment. After $72 \mathrm{~h}$, root-end preparations and root-end fillings were performed by a single operator under a surgical microscope (Global, St Louis, MO, USA) at $\times 8$ magnification. Feather-like back and forth motions were applied with a slight coronal pressure using p5 ultrasonic (Spartan, Fenton, MO, USA) and water cooling. The same power was used in all cases throughout the experiment. A new retro-tip (KiS tips; Spartan, Fenton, MO, USA) was used for each root preparation. The lengths and radii of the retro-tips $(3 \mathrm{~mm})$ determined the depth of the root-end cavities and their final diameter.
The crowns of the teeth were then sectioned with a slow-speed diamond saw (Isomet; Buehler, Lake Bluff, IL, USA) under water coolant. On the basis of each treatment performed, the teeth were randomly divided into four groups ( $n=16$ per group) by picking a paper from a brown bag marked 'group 1', 'group 2', 'group 3' or 'group 4'. In group 1 (WMTA), root-end preparations were obturated with ProRoot whitecolored MTA (Dentsply Tulsa, Tulsa, OK, USA). In group 2 (etched WMTA, EWMTA), the inner cavity surfaces were pre-etched with $37 \%$ phosphoric acid (Ultra Etch; Dentsply, York, PA, USA) for $20 \mathrm{~s}$, thoroughly rinsed with water for $15 \mathrm{~s}$, gently air dried and obturated with WMTA. In group 3 (gray-colored MTA, GMTA), root-end preparations were obturated with GMTA (Dentsply Tulsa, Tulsa, OK, USA) and in group 4 (etched GMTA, EGMTA) root-end preparations were pre-etched with phosphoric acid (as described in group 2) and then obturated with the GMTA. A plastic instrument and MTA apical pluggers (Machtou Dentsply Maillefer, Surrey, UK) were used to condense the retrofilling material. Excessive MTA material was removed with a plastic instrument (Hu-Friedy, Chicago, IL, USA).

\section{Microcomputed tomography}

After 48 h, all teeth were scanned using a micro-CT (model 1172; Skyscan, Kontich, Belgium) and three-dimensional micro-CT images were constructed to analyze the gap volume present between the root canal obturation, apical filling material and root dentin. During the scanning process, each tooth was wrapped in Parafilm (ChemNet; Parafilm, West Chester, PA, USA) to prevent desiccation. Specimens were scanned at $110 \mathrm{kV}$ and $96 \mu \mathrm{A}$ with a resolution of $37.4 \mu \mathrm{m}$ using a 1-mm-thick aluminum filter and $54 \%$ beam hardening reduction. The region of interest was specified as an annular area with a diameter of $1.7 \mathrm{~mm}$ surrounding the tooth over a length of $3 \mathrm{~mm}$.

\section{Scanning electron microscopy}

All specimens were examined using a SEM device (JSM-5800 LV; Jeol, Tokyo, Japan) for marginal adaptation in axial and sagittal directions. Teeth were sectioned in a sagittal direction parallel to the long axis of the root canal (Figure 1). Each tooth was wrapped in Parafilm prior to
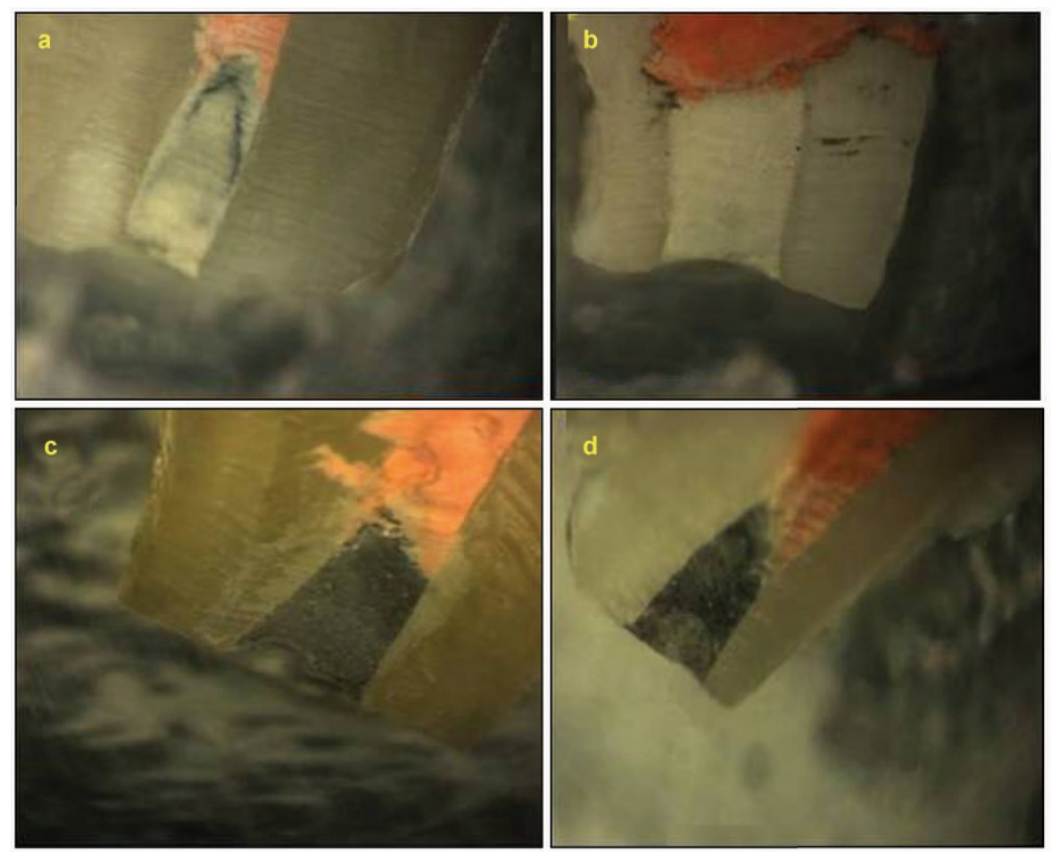

Figure 1 Photomicrograph of apical root showing root end filling material adaptation to root dentin and the gutta-percha canal filling in sagittal view. (a) WMTA, white-colored mineral trioxide aggregate; (b) EWMTA, etched white-colored mineral trioxide aggregate; (c) GMTA, gray-colored mineral trioxide aggregate; (d) EGMTA, etched gray-colored mineral trioxide aggregate. 

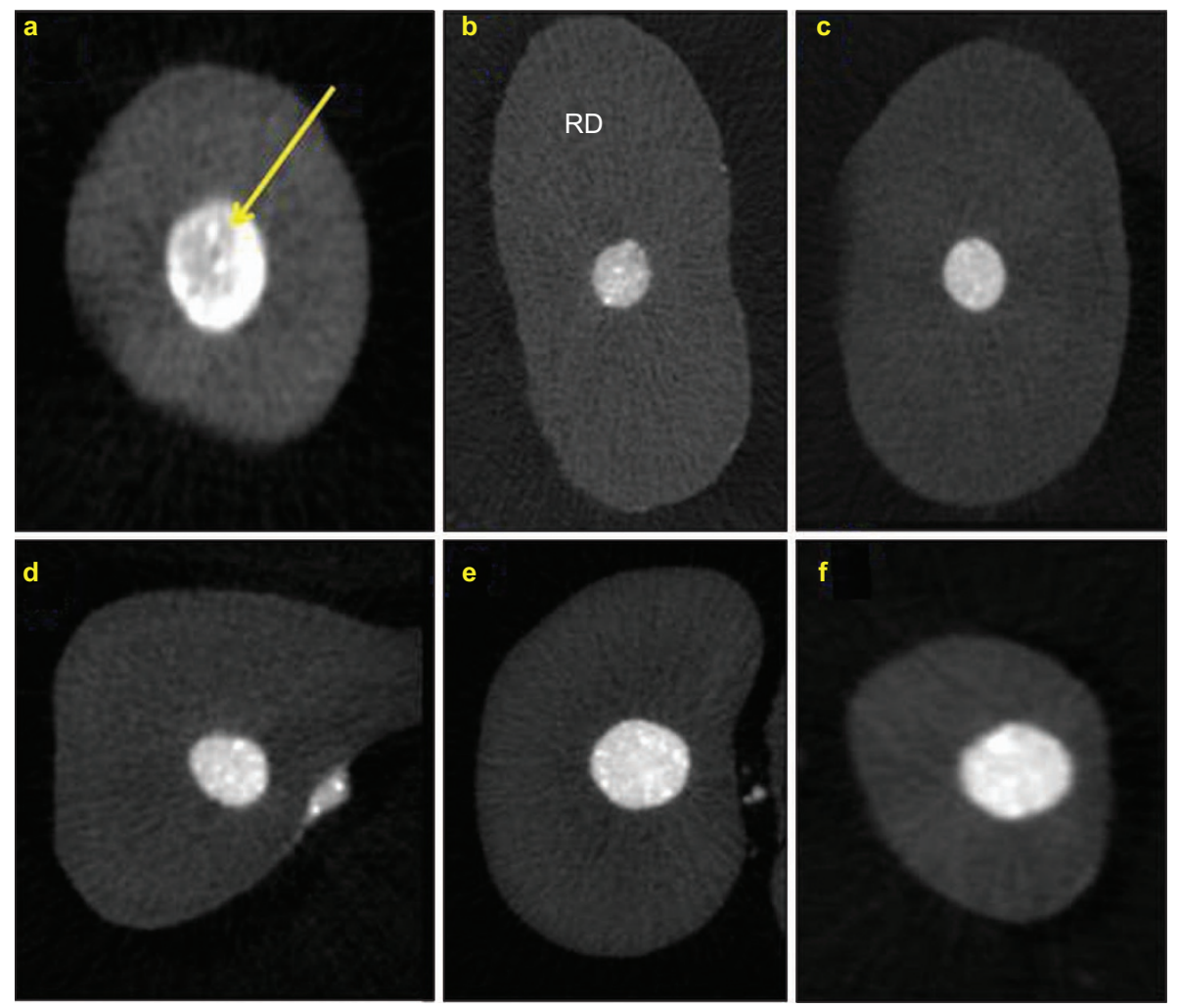

Figure 2 Reconstructed axial section images (at $0.5 \mathrm{~mm}$ each) showing absence of voids following treatment. (a-c) Treated with WMTA; (d-f) treated with EWMTA. Arrow indicates complete seal with no gap. WMTA, white-colored mineral trioxide aggregate; EWMTA, etched white-colored mineral trioxide aggregate.

SEM scanning prevent desiccation. Sagittal examination was performed after longitudinal sectioning of the roots. Microphotographs were taken and analyzed using Image Tool 3.0 custom software (UTHSCSA, San Antonio, TX, USA). The functions of the Image tool program include dimensional (distance, angle, perimeter, area) and gray scale measurements (point, line and area histogram with statistics). This software also supports standard image processing functions such as contrast manipulation, sharpening, smoothing, edge detection, median filtering and spatial convolutions with user-defined convolution masks. It also has built-in scripting capabilities that allow the user to record repetitive tasks and playback saved scripts to automate image analysis. The gap size was measured at four opposite land points in the axial sections.

\section{Statistical analysis}

Statistical analysis was performed using Kruskal-Wallis and the Dunn tests at $95 \%$ level of significance. Means of the length and width of each gap were calculated and analyzed by a software program (SPSS Inc., Chicago, IL, USA).

\section{RESULTS}

Reconstructed longitudinal micro-CT images showed gap volumes of $(0.0059 \pm 0.002) \mathrm{mm}^{3}$ and $(0.0036 \pm 0.001) \mathrm{mm}^{3}$ for WMTA and EWMTA, respectively. No significant difference in gap volumes between WMTA (Figure 2a-2c) and EWMTA (Figure 2d-2f) were found.

Gap volumes of $(0.053 \pm 0.002) \mathrm{mm}^{3}$ for GMTA (Figure $3 \mathrm{a}-3 \mathrm{c}$ ) and $(0.0071 \pm 0.004) \mathrm{mm}^{3}$ for EGMTA (Figure $3 \mathrm{~d}-3 \mathrm{f}$ ) were found. Significant differences in the gap volumes between GMTA and EGMTA were found $(P<0.001)$.

\section{Scanning electron microscopy}

Axialscanning. Gapsizes forEWMTA(Figure 4a) and WMTA (Figure 4b) by SEM were (203.2 \pm 9.56$) \mu \mathrm{m}$ and $(298.5 \pm 11.02) \mu \mathrm{m}$, respectively.
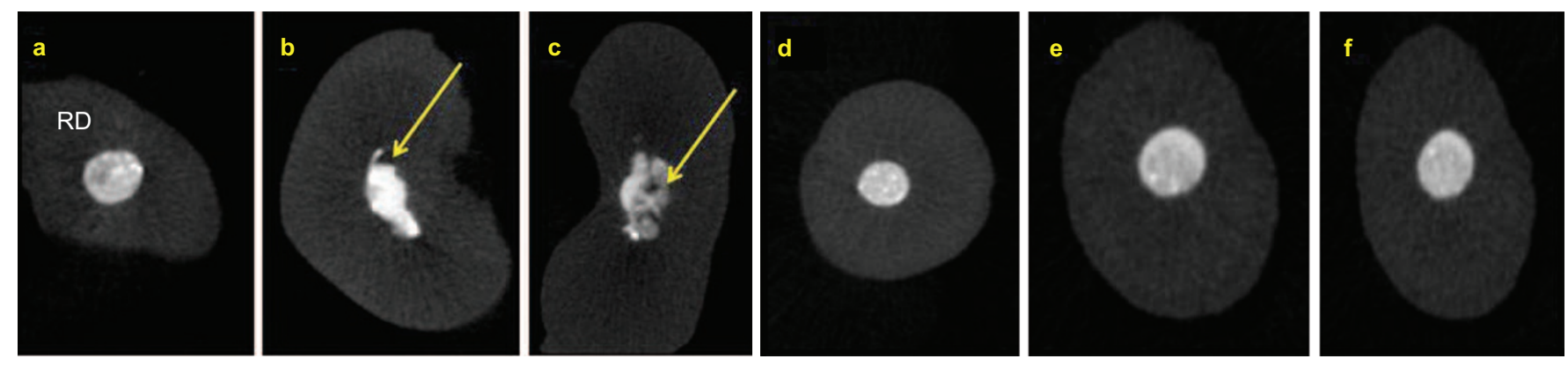

Figure 3 Reconstructed axial section images (at $0.5 \mathrm{~mm}$ each). (a-c) GMTA group, showing presence of voids and incomplete adaptation of root-end filling material to dentin walls (solid arrow). (d-f) EGMTA group, showing absence of voids. GMTA, gray-colored mineral trioxide aggregate; EGMTA, etched gray-colored mineral trioxide aggregate. 

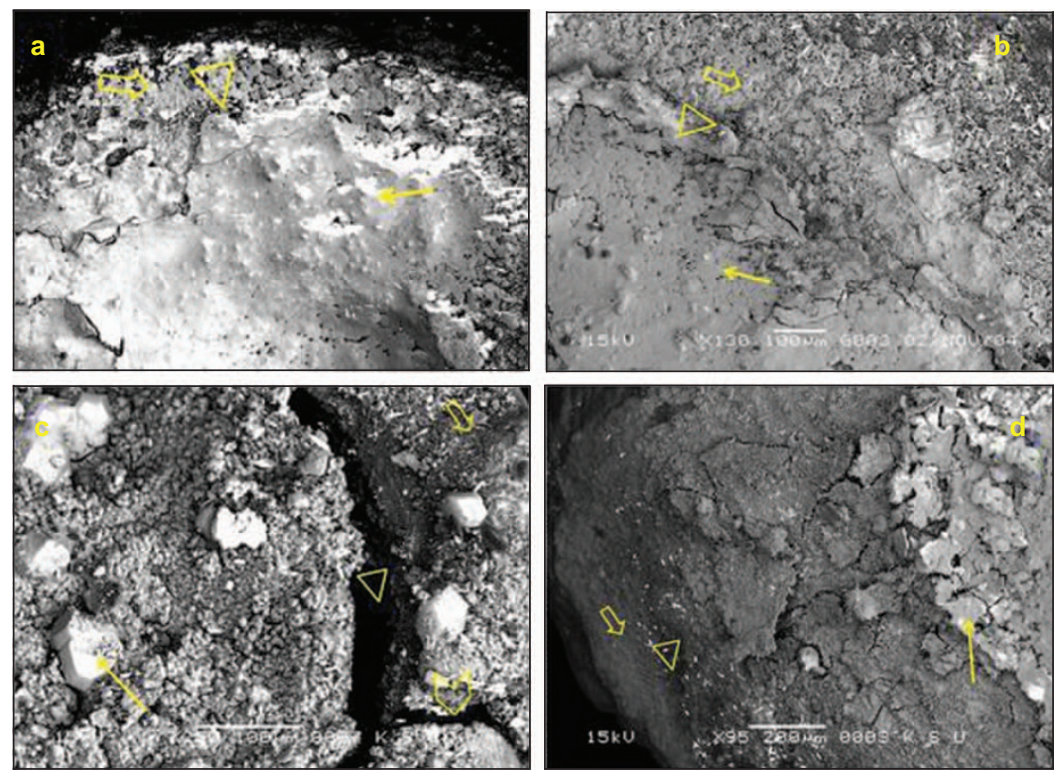

Figure 4 SEM photomicrographs at the root apex in axial view, showing marginal adaptation and interface between each material tested and dentin walls. (a) EWMTA, etched white-colored mineral trioxide aggregate; (b) WMTA, white-colored mineral trioxide aggregate; (c) GMTA, gray-colored mineral trioxide aggregate; (d) EGMTA, etched gray-colored mineral trioxide aggregate. Solid arrow indicate the retrograde material; open arrow to the root dentin; triangle to the gap. SEM, scanning electron microscopy.

Gap sizes for GMTA (Figure 4c) and EGMTA (Figure 4d) were $(210.7 \pm 12.46) \mu \mathrm{m}$ and $(162.3 \pm 8.71) \mu \mathrm{m}$, respectively and the difference was statistically significant $(P<0.01)$.
Sagittal scanning. Groups of WMTA (Figure 5a and 5b) and EWMTA (Figure $5 \mathrm{c}$ and $5 \mathrm{~d}$ ), showed gaps between the root end obturation material and the apical dentin interface of $(594.5 \pm 17.12) \mu \mathrm{m}$ and
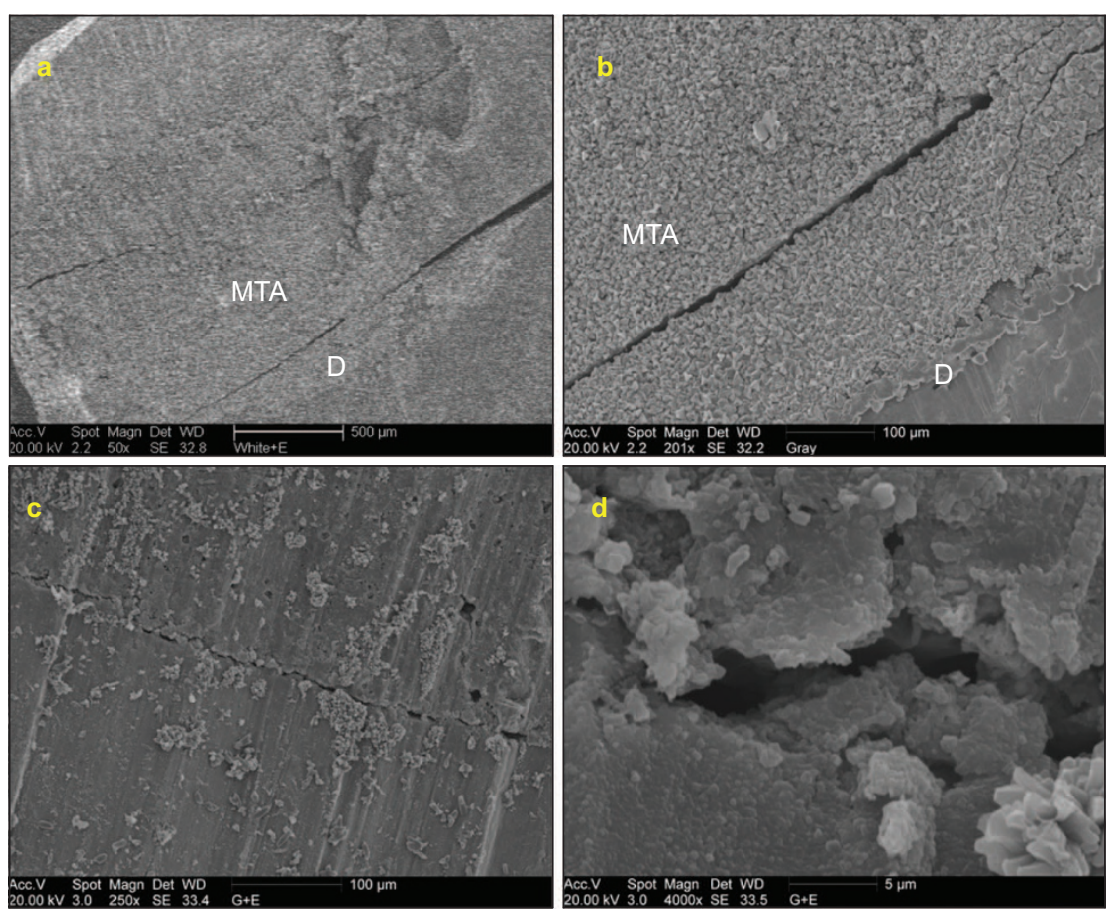

Figure 5 SEM photomicrographs in sagittal view, showing retrofilling material/dentin interface. (a, b) WMTA, gray without etch; (c, d) EWMTA, gray with etch. D, dentin; MTA, mineral trioxide aggregate; WMTA, white-colored mineral trioxide aggregate; EWMTA, etched white-colored mineral trioxide aggregate; SEM, scanning electron microscopy. 

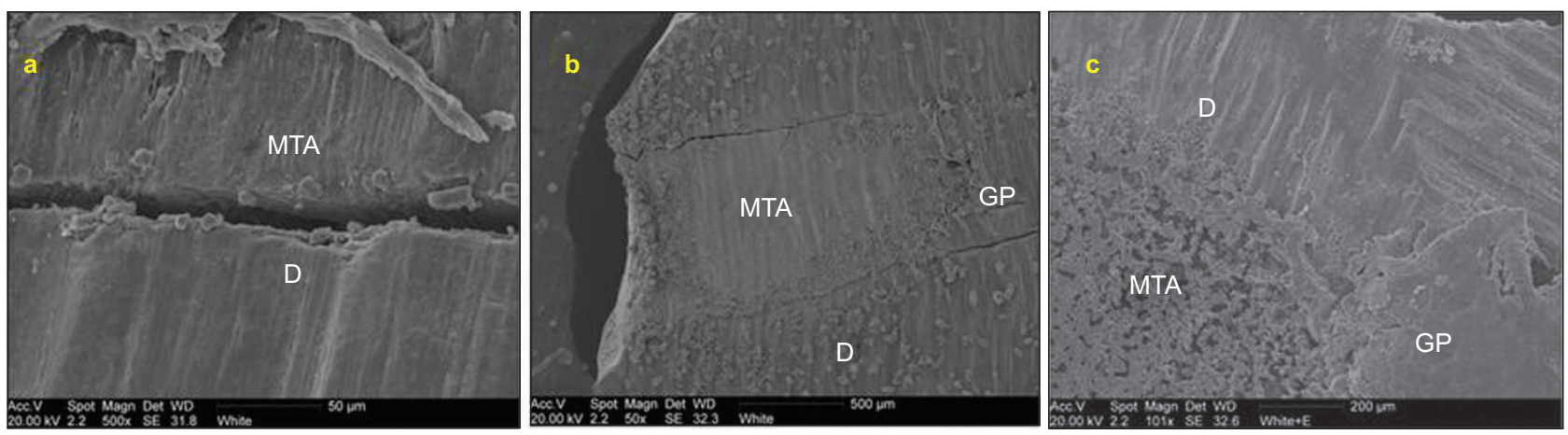

Figure 6 SEM photomicrographs in sagittal view, showing retrofilling material/dentin interface. (a, b) GMTA, white without etch; (c) EGMTA, white with etch. D, dentin; GA, gutta percha; MTA, mineral trioxide aggregate; GMTA, grey-colored mineral trioxide aggregate; EGMTA, etched gray-colored mineral trioxide aggregate; SEM, scanning electron microscopy.

(543.1 \pm 15.33$) \mu \mathrm{m}$, respectively. GMTA showed a significantly larger marginal gap size with mean size of $(910.7 \pm 26.2) \mu \mathrm{m}$ (Figure $6 \mathrm{a}$ and $6 \mathrm{~b}$ ). EGMTA showed a mean gap size of $(492.3 \pm 13.8) \mu \mathrm{m}$ (Figure $6 \mathrm{c})$. The difference between the GMTA and EGMTA was statistically significant $(P<0.001)$.

\section{DISCUSSION}

According to the present results, pre-etching dentin with $37 \%$ phosphoric acid enhanced the marginal adaptation of GMTA to dentin as compared to WMTA that failed to demonstrate adequate adaptation following pre-etching. This variation in marginal adaptation between the two aggregates may be associated to the differences in the physical and chemical properties of the two materials. It has been reported that the antimicrobial efficacy of GMTA is significantly higher that of WMTA even at lower concentrations. ${ }^{11,20-22}$ GMTA preparation is a fine hydrophilic powder that is composed of calcium, phosphorus, iron and bismuth oxide and contains small-sized aggregate particles as compared to WMTA. ${ }^{22-26}$ Such variations in structure and composition may cause the material to have different levels of marginal adaptation to root dentin. It order to achieve a better marginal adaptation of the gray-colored aggregate to pre-etched dentin, the exact physical and chemical properties of the material and the dentin exposed to phosphoric acid should be further explored. This may shed further light on the mechanism of adaptation of MTA to pre-etched root-end cavity preparations.

Previous studies ${ }^{27-29}$ have reported that acid etching induces moderate to severe pulpal reactions. This is attributed to the fact that acid etching of dentin, (regardless of the concentration of phosphoric acid), causes removal of the smear layer and exposes the apertures of dentinal tubules thereby providing a gateway to the bacteria and their products into the pulp chamber. ${ }^{30}$ Since WMTA exhibits a poorer antimicrobial efficacy and tends to 'leak' more as compared to GMTA; $;^{20-21,31}$ it is tempting to speculate that placement of WMTA on pre-etched dentin would facilitate bacterial migration into the pulp chamber and exacerbate the healing process. On the contrary, placement of GMTA on pre-etched dentin is expected to induce (if not prevent) pulpal reactions to a relatively lesser extent due to the lower setting expansion and antimicrobial potential of GMTA. ${ }^{20-21,31}$ However, further studies are warranted in this regard.

It is concluded that within the limitations of the present study, acid etching of apical dentine prior to placement of GMTA can improve marginal adaptation of the material to root end cavity preparation.
1 Chng HK, Islam I, Yap AU et al. Properties of a new root-end filling material. J Endod 2005; 31(9): 665-668.

2 Tobón-Arroyave SI, Restrepo-Pérez MM, Arismendi-Echavarría JA et al. Ex vivo microscopic assessment of factors affecting the quality of apical seal created by root-end fillings. Int Endod J 2007; 40(8): 590-602.

3 Porter ML, Bertó A, Primus CM et al. Physical and chemical properties of newgeneration endodontic materials. J Endod 2010; 36(3): 524-528.

4 Yildirim T, Er K, Taşdemir T et al. Effect of smear layer and root-end cavity thickness on apical sealing ability of MTA as a root-end filling material: a bacterial leakage study. Oral Surg Oral Med Oral Pathol Oral Radiol Endod 2010; 109(1): e67-e72.

5 Stabholz A, Friedman S, Abed J. Marginal adaptation of retrograde fillings and its correlation with sealability. J Endod 1985; 11(5): 218-223.

6 Al-Hezaimi K, Naghshbandi J, Oglesby S et al. Human saliva penetration of root canals obturated with two types of mineral trioxide aggregate cements. J Endod 2005; 31(6): 453-456.

7 Al-Hezaimi K, Al-Hamdan K, Naghshbandi J et al. Effect of white-colored mineral trioxide aggregate in different concentrations on Candida albicans in vitro. J Endod 2005; 31(9): 684-686.

8 Maltezos C, Glickman GN, Ezzo P et al. Comparison of the sealing of Resilon, Pro Root MTA, and Super-EBA as root-end filling materials: a bacterial leakage study. J Endod 2006; 32(4): 324-327.

9 Ribeiro DA, Sugui MM, Matsumoto MA et al. Genotoxicity and cytotoxicity of mineral trioxide aggregate and regular and white Portland cements on Chinese hamster ovary (CHO) cells in vitro. Oral Surg Oral Med Oral Pathol Oral Radiol Endod 2006; 101(2): 258-261.

10 Al-Hezaimi K, Al-Shalan TA, Naghshbandi J et al. MTA preparations from different origins may vary in their antimicrobial activity. Oral Surg Oral Med Oral Pathol Oral Radiol Endod 2009; 107(5): e85-e88.

11 Reyes-Carmona JF, Felippe MS, Felippe WT. Biomineralization ability and interaction of mineral trioxide aggregate and white portland cement with dentin in a phosphatecontaining fluid. J Endod 2009; 35(5): 731-736.

12 Tawil PZ, Trope M, Curran AE et al. Periapical microsurgery: an in vivo evaluation of endodontic root-end filling materials. J Endod 2009; 35(3): 357-362.

13 Orosco FA, Bramante CM, Garcia RB et al. Sealing ability, marginal adaptation and their correlation using three root-end filling materials as apical plugs. J Appl Oral Sci 2010; 18(2): 127-134

14 Parirokh M, Torabinejad M. Mineral trioxide aggregate: a comprehensive literature review-Part III: Clinical applications, drawbacks, and mechanism of action. $J$ Endod 2010; 36(3): 400-413.

15 Parirokh M, Torabinejad M. Mineral trioxide aggregate: a comprehensive literature review-Part I: chemical, physical, and antibacterial properties. J Endod 2010; 36(1): 16-27.

16 Torabinejad M, Smith PW, Kettering JD et al. Comparative investigation of marginal adaptation of mineral trioxide aggregate and other commonly used root-end filling materials. J Endod 1995; 21(6): 295-299.

17 Shipper G, Grossman ES, Botha AJ et al. Marginal adaptation of mineral trioxide aggregate (MTA) compared with amalgam as a root-end filling material: a lowvacuum (LV) versus high-vacuum (HV) SEM study. Int Endod J 2004; 37(5): 325-336.

18 Bidar M, Moradi S, Jafarzadeh $\mathrm{H}$ et al. Comparative SEM study of the marginal adaptation of white and grey MTA and Portland cement. Aust Endod J 2007; 33(1): 2-6.

19 Komabayashi T, Spångberg LS. Comparative analysis of the particle size and shape of commercially available mineral trioxide aggregates and Portland cement: a study with a flow particle image analyzer. J Endod 2008; 34(1): 94-98.

20 Al-Hezaimi K, Al-Shalan TA, Naghshbandi J et al. Antibacterial effect of two mineral trioxide aggregate (MTA) preparations against Enterococcus faecalis and Streptococcus sanguis in vitro. J Endod 2006; 32(11): 1053-1056. 
21 Al-Hezaimi K, Naghshbandi J, Oglesby S et al. Comparison of antifungal activity of white-colored and gray-colored mineral trioxide aggregate (MTA) at similar concentrations against Candida albicans. J Endod 2006; 32(4): 365-367.

22 Torabinejad M, Hong CU, McDonald F et al. Physical and chemical properties of a new root-end filling material. J Endod 1995; 21(7): 349-353.

23 Asgary S, Parirokh M, Eghbal MJ et al. Chemical differences between white and gray mineral trioxide aggregate. J Endod 2005; 31(2): 101-103.

24 Sarkar NK, Caicedo R, Ritwik P et al. Physicochemical basis of the biologic properties of mineral trioxide aggregate. J Endod 2005; 31(2): 97-100.

25 Song JS, Mante FK, Romanow WJ et al. Chemical analysis of powder and set forms of Portland cement, gray ProRoot MTA, white ProRoot MTA, and gray MTAAngelus. Oral Surg Oral Med Oral Pathol Oral Radiol Endod 2006; 102(6): 809815.

26 Asgary S, Parirokh M, Eghbal MJ et al. A qualitative X-ray analysis of white and grey mineral trioxide aggregate using compositional imaging. J Mater Sci Mater Med2006; 17(2): 187-191.

$27 \mathrm{Kiba} \mathrm{H}$, Hayakawa T, Nakanuma K et al. Pulpal reactions to two experimental bonding systems for pulp capping procedures. J Oral Sci 2000; 42(2): 69-74.
28 da Silva LA, de Freitas AC, de Carvalho FK etal. Direct pulp capping with a self-etching adhesive system: histopathologic evaluation in dogs' teeth. Oral Surg Oral Med Oral Pathol Oral Radiol Endod 2009; 108(1): e34-e40.

29 Nayyar S, Tewari S, Arora B. Comparison of human pulp response to total-etch and self-etch bonding agents. Oral Surg Oral Med Oral Pathol Oral Radiol Endod 2007; 104(2): e45-e52.

30 Matos AB, Palma RG, Saraceni $\mathrm{CH}$ et al. Effects of acid etching on dentin surface: SEM morphological study. Braz Dent J 1997; 8(1): 35-41.

31 Matt GD, Thorpe JR, Strother JM et al. Comparative study of white and gray mineral trioxide aggregate (MTA) simulating a one- or two-step apical barrier technique. J Endod 2004; 30(12): 876-879.

(c)

This work is licensed under a Creative Commons

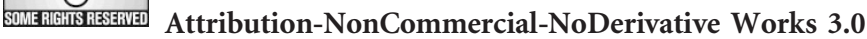
Unported License. To view a copy of this license, visit http:// creativecommons.org/licenses/by-nc-nd/3.0 